\title{
Circularly Polarized (CP) Wideband on Fabric (Textile) Stealth MIMO Antenna for Wearable Wireless UWB Applications
}

Pillalamarri Laxman ( $\sim$ laxmanabcd@gmail.com)

Afghanistan Research and Evaluation Unit

ANUJ JAIN

Afghanistan Research and Evaluation Unit

\section{Research Article}

Keywords: Bending-effects, CP, polarization, stealth , radiating element, stealth-wearable antenna. Patch antenna

Posted Date: October 21st, 2021

DOI: https://doi.org/10.21203/rs.3.rs-833165/v1

License: (c) (i) This work is licensed under a Creative Commons Attribution 4.0 International License.

Read Full License 


\title{
Circularly Polarized (CP) Wideband on Fabric (Textile) Stealth MIMO Antenna for Wearable Wireless UWB Applications
}

\author{
Pillalamarri. Laxman, \\ School Of Electronics and Electrical Engineering. \\ E-mail: a Laxmanpillalamarri@gmail.com, laxmanabcd@gmail.com .
}

Dr. Anuj Jain, School Of Electronics and Electrical Engineering, eMail : a1978jain@gmail.com .

\begin{abstract}
Stealth wearable wireless devices gained popularity in the personal security and fashion design industry. A multiple-input-output (MIMO) wideband circularly polarized textile is described in the present paper, where a wearable application uses a multiple-input-output (M.I.M.O). It consists of two MIMO antennas, the resonating elements are shaped like a peacock, and the ground plane is similar to a beautiful peacock. A voltage is applied to each antenna element; the ground plane contains a a Peacock-shaped small strip antenna used for circular polarizing. The antenna covers $3 \mathrm{~dB}$ Axial Ratio Band-Width (A.R.B.W.) of 5.0-7.0 GHz and impedance bandwidth (S11 $\leq-10.5$ $\mathrm{dB}$ ) of 3.7-13.5 GHz. The improved fabric-textile Multple-input-multiple-output antenna showing Channel-Capacity-Loss about (C.C.L) $<0.20 \mathrm{bits} / \mathrm{sec} / \mathrm{Hz}$, \& Envelope-Correlation-Coefficient (E.C.C) less than 0.021, Total Active-Reflective-Coefficient (T.A.R.C) close to $-10.4 \mathrm{~dB}$, DiversityGain (D.G) close to 9.96, Mean-Effective-Gain (M.E.G) ratio close to $\pm 0.5 \mathrm{~dB}$. A Specific-Absorption-Rate(S.A.R) of the proposed antenna for tissues of human specimens is also discussed for different situations pertaining to the human body. The final dimention of the presented Circularly-Polarized textile wearable Multple-input-multiple-output antenna is $34: 5 \times 41 \times 1.1 \mathrm{~mm} 3$. The proposed antenna can make unrecognizable because of the beautiful peacock design that can easily mix with the designs of fabric.
\end{abstract}

\section{INDEX TERMS}

Bending-effects, CP, polarization, stealth, radiating element, stealth-wearable antenna. Patch antenna

\section{Prior Art and Problem Definition}

Designers are paying considerable attention to wearable gadgets because of their numerous uses in communication gadgets, and safety devices [1], [2]. The radiating element is a crucial component of a any transceiver system. To radiate efficiently through bending, running, running, and movement, wearable/textile antennas are required. Antennas on textiles must be easy-to-integrate into miniature electronic consumer devices or fashion-clothing and must be low-size, low in weight, non-fragile, durable [3]. Fabrication, antenna placement, and structural deformation are all factors to consider when designing textile antennas [4], [5]. In addition to their flexibility in orientation, movability, and immunity to interference from all drections, wearable applications requiring circularly polarized besides wide-band quality antennas are becoming increasingly in demand [6] -[8]. A growing number of companies are focusing on multi-input-multi-output (M.I.M.O.) and diversity 
technologies to improve transmission-capacity, especially in complicated multi-path mediums. For establishing reliable channels and dealing with multipath fading, multielement antennas with polarization diversity are the best choice [9]-[11].

There have been several text-tile Multple-Input-Multiple-Output radiating-dipoles with high interelement isolation introduced in the reference [12]-[17]. In ref[12], vias are used to change the modes of resonance of the cavity waveguide with two-band Multple-input-multiple-output antenna generally suitable for W-LAN devices.

An antenna-design with a circular shape and a high impedance surface (HIS) has been described [13], with an excellent isolation of $15-\mathrm{dB}$ between the ports. Wearable applications were demonstrated using a textile MIMO antenna embedded in a single-coated fabric [14][15].. An Ishaped stub was exploited to get larger interelement isolation on a square-shaped wearable Multpleinput-multiple-output antenna described in [16]. An inverted-L planar strip ground plane was used in [17] to achieve a wide axial ratio bandwidth (ARBW) by feeding a C.P.W wave guide( Coplanar) into a rectangualar slot Multple-input-multiple-output antenna. It was reported in [18] that a dual CP antenna could be formed by combining $L$-shaped strips to achieve polarization of circular nature. The ground plane of [19] was proposed with a twisted $F$-shaped with a defected-ground-structure (D-GS) combined with a Circularly polarized Multple-input-multiple-output antenna composed of stubs that are clearly grounded. It is shown in [20] that the orthogonal field induction is achieved through the modification of the ground plane of the CP antenna. According to [21], a grounded antenna with wearable on cloths can navigate the phasar differences around orthogonal modes using an implanted in the ground. In [12]-[16], Multple-input-multiple-output antennas showed linear polarization (LP) characteristics, while the references [17] to [21], Circularly polarization characteristics were presented. There have been very few reports of wearable/textile antennas that have a wide ARBW. Most wearable on fabric antennas in the literature are Linear-polarization with only single element configurations having very narrow axial ratio bandwidths (A.R.B.W). The ref[31] has given a brief intuition to the present proposed antenna design. The present paper disclosed more attractive, swift anonymous antenna which can be placed disguised as a regular artwork on designer made wearable dress.

An article based on robust, low-sized, wearable-on-cloth, 2-element Circularly Polarized ultpleinput-multiple-output wearable-antennas for mobile communications devices is presented here. It comprises a Peacock-shaped micro-strip(MS) line-fedd antenna and a suitable ground plane. Using an $L$-figured stub, a quad- phase shift is introduced between the vertical \& horizontal E-field vectors. Dual-sensor radiation characteristics are achieved by locating the 2-radiating elements in a mirrorimaging configuration. CP (left-hand CP) waves are emitted by port-1, while CP waves (right-hand $\mathrm{CP}$ ) are emitted by port-2. Due to this property, the presented multple-input-multiple-output antenna is appropriate for polarization-diversity.

\section{CONFIGURATION of Presented STEALTH Radiator} A. ANTENNA ELEMENT CREATION 
The disclosed Circularly polarized wearable antenna element is illustrated in Fig.1. Antenna element dimensions are $20 \mathrm{~mm} \times 30: 5 \mathrm{~mm}$. On the lower $\&$ upper sides of the dielectric material, the radiating element consists of a Peacock-shaped antenna microstrip and a specific ground plane, shown in Figs. 1(B) and (C). The antenna element consists of a $1.0 \mathrm{~mm}$ thick material of Felt as a base substrate, with a dielectric constant of 1.34, and a LossTangent value of 0.02. A Shielded Superconductive material of depth $0.171 \mathrm{~mm}$ and a surface resistance of $0.5 \Omega$ /square is used to produce the antenna strip and the grounding-plane. An HFSS R simulation is performed using ANSYS HFSS R software to simulate the proposed antenna. The antenna is supplied by a $50 \mathrm{ohms}$ Striplne.
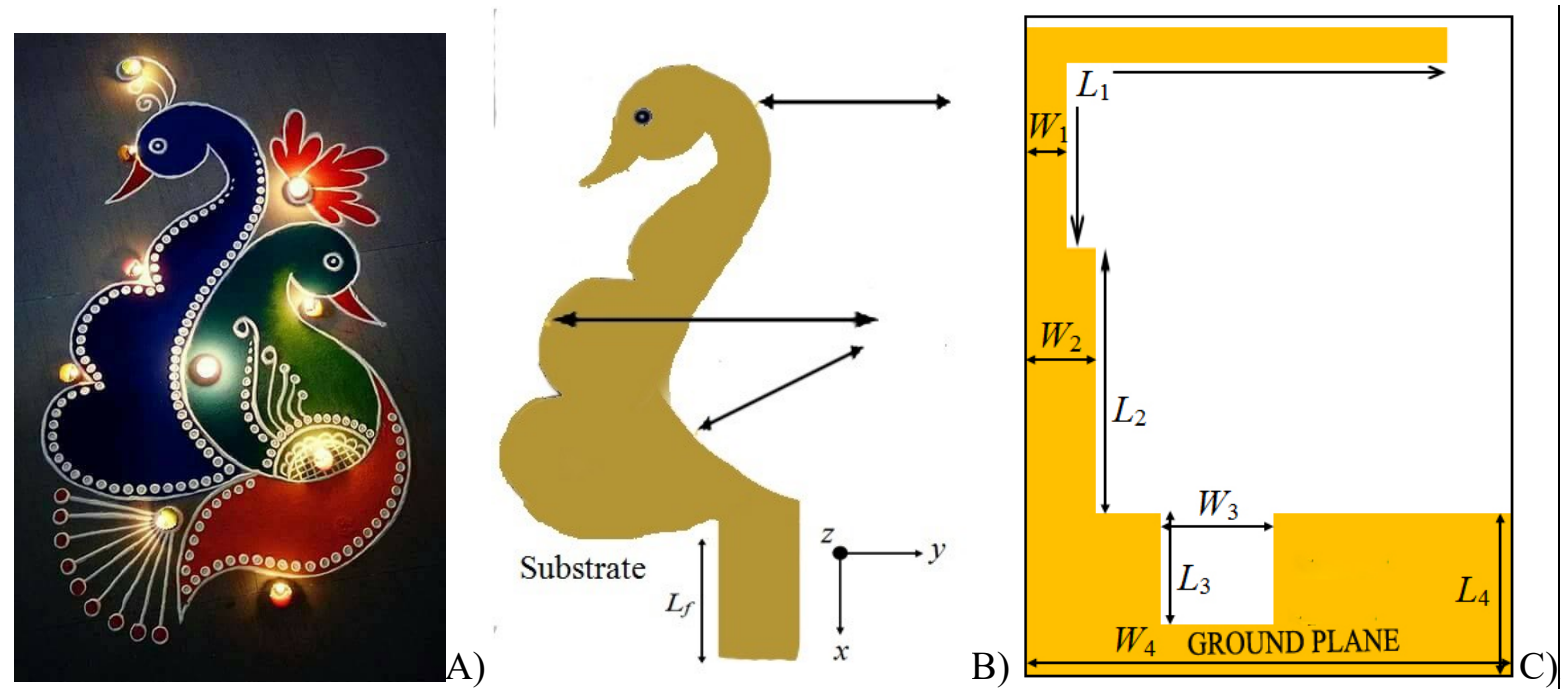

Fig-1.Presented Stealth Circularly polarized wearable antenna A)Stealth Fabric Design in Color B)TOP side View C)Bottom side View(Left to right side counting).

The design parameters of the antenna element are: $R 1=, 11: 51$ milli-meters, $R 2=10.31$ milli-meters, $R 3=13.7$ milli-meters, $L f=10.190$ milli-meters, $L 1=22$. milli-meters, $W 1=1.711$ milli-meters, $L 2=11.0$ milli-meters, $W 2=3.1$ milli-meters, $L 3=5.6$ milli-meters, $W 3=5.1$ milli-meters, $L 4=7: 69$ milli-meters, $W 4=21.1 \mathrm{~mm}$. 


$$
\begin{aligned}
& 224 \\
& 23
\end{aligned}
$$


11.29GHz]. The second step as depicted in Figure-2(b), adds a microstrip of wavelength half-lambda to the ground plane to improve the bandwidth-impedance. Two resonating bands are also visible in ANTENNA-2.
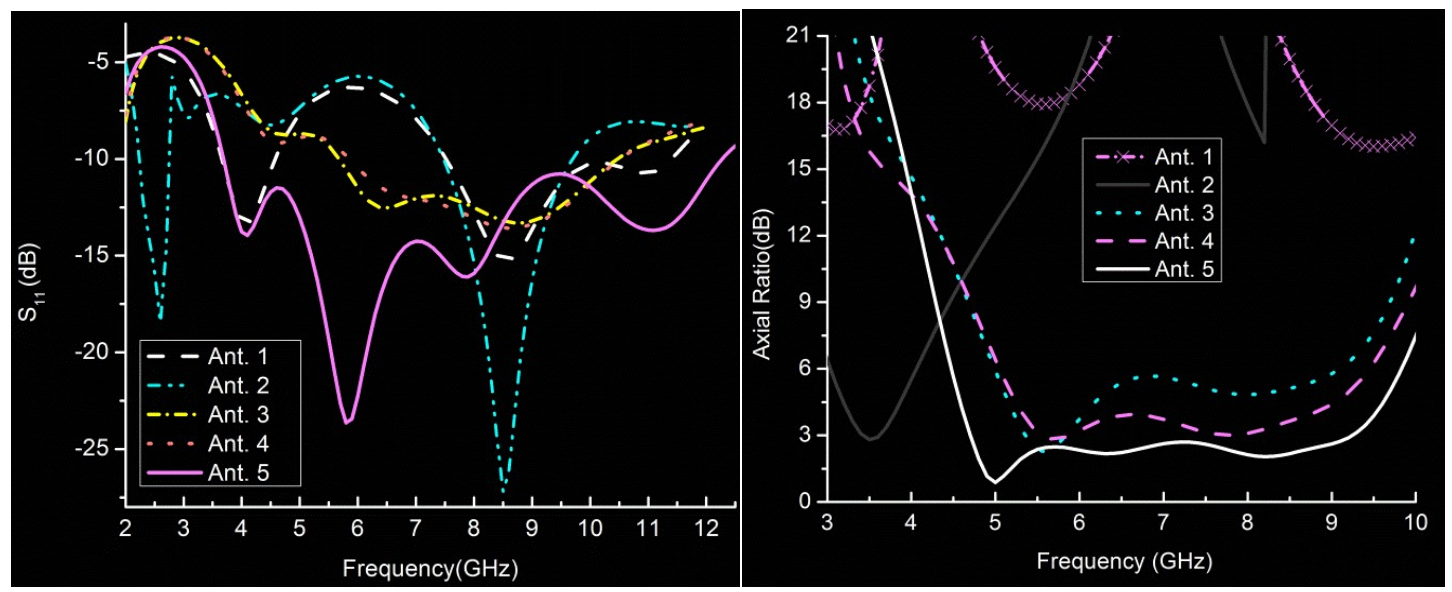

FIG 3. Software given results of the designing phases: (a) coefficient of reflection, (b) axial ratio.

An L-type microstrip inserted in the GroundPlane(GP) (ANTENNA-3) overcomes the impedance mismatch, as descibed in Figure.2-c. Besides the L-type strip, the voltages induced by the two Efield vectors $\left(\mathrm{E}_{\mathrm{x}} \& \mathrm{E}_{\mathrm{y}}\right)$ are also in the quadrature phase difference. $5.5-10.4 \mathrm{GHz}$ and $5.3-5.8 \mathrm{GHz}$ are the impedance and ARBWs of the ANTENNA-3. By alienating the L-TYPE MICROSTRIP into 2-divisions (of $\mathrm{L} 2 * \mathrm{~W} 2$ and $\mathrm{L} 1 * \mathrm{~W} 1$ ), as illustrated in Figure.2-d, one can improve the axial ratio of the radiating element (ANTENNA-4) in step-4. To cover the lower frequency range, the RADIATOR resonating band required to change to the left-side. The antenna element therefore has a rectangular slot (with dimensions L $3 * \mathrm{~W} 3$ ) etched in its ground plane, as can be observed in Figure. 2e. Therefore, the current operating frequency band moves to the downward diirection when the path length grows. In addition, the proposed ANTENNA-5 achieves superior CP performance. In Table-1, you will find the simulation results (impedance band width \& ARBW) of every stage.

\section{2) CIRCULAR POLARIZATION (CP) PERFORMANCE}

Antenna stages are illustrated in Fig.3(b) indicating the axial ratios and frequency. The ANTENNA1 vector@ stage-1 is Linearly Polarized as the vector Phase-Contrast(PC) between the E-field vectors is never 90 degrees. Likewise, ANTENNA-2 is also Linearly Polarization.

TABLE 1. Correlation of computer-generated results of the design stages.

\begin{tabular}{|l|l|l|l|}
\hline Step & B.W(Giga hertz) & $\begin{array}{l}\text { Fractional } \\
\text { BW(\%) }\end{array}$ & $\begin{array}{l}\text { Axial } \\
\text { Ratio BW } \\
\text { (Giga } \\
\text { hertz) }\end{array}$ \\
\hline ANTENNA.1 & $3.0-4.51,7.51-11.31$ & 22.221, & \\
\hline
\end{tabular}




\begin{tabular}{|l|l|l|l|}
\hline & & 25.234 & \\
\hline ANTENNA.2 & $2.21-2.87, \quad 7.4-9.6$ & $16.6, \quad 16.54$ & \\
\hline Ant.3 & $5.5-10.39$ & 64.149 & $5.31-5.78$ \\
\hline $\begin{array}{l}\text { ANTENNA.5 } \\
\text { (Proposed) }\end{array}$ & $3.69-12.19$ & 106.95 & $4.7-9.21$ \\
\hline
\end{tabular}

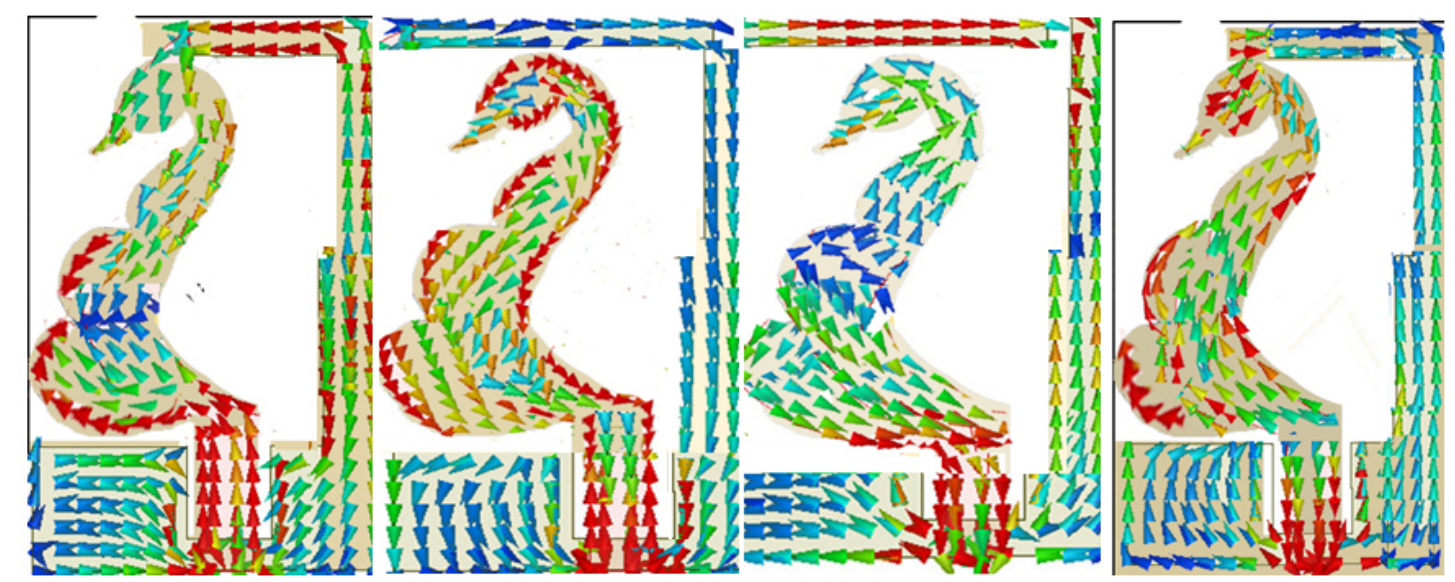

FIG 4. Vector current spanning across 4.25Ghz: (a) 0degree, (b) 90degree, (c) 180degree, (d) 270 degrees.(Left to right fig counting)

Furthermore, a square ground-plane (Antenna-3 and Antenna-4) is joined to a series of Letter-Lfashioned strips of various widths \& lengths to obtain a 90-degree differences of phase among the Efield vectors. X-axis fiels(Ex) and y-axis field(Ey) amplitudes become almost equal when they are separated by $90 *$ phase deviation [17].
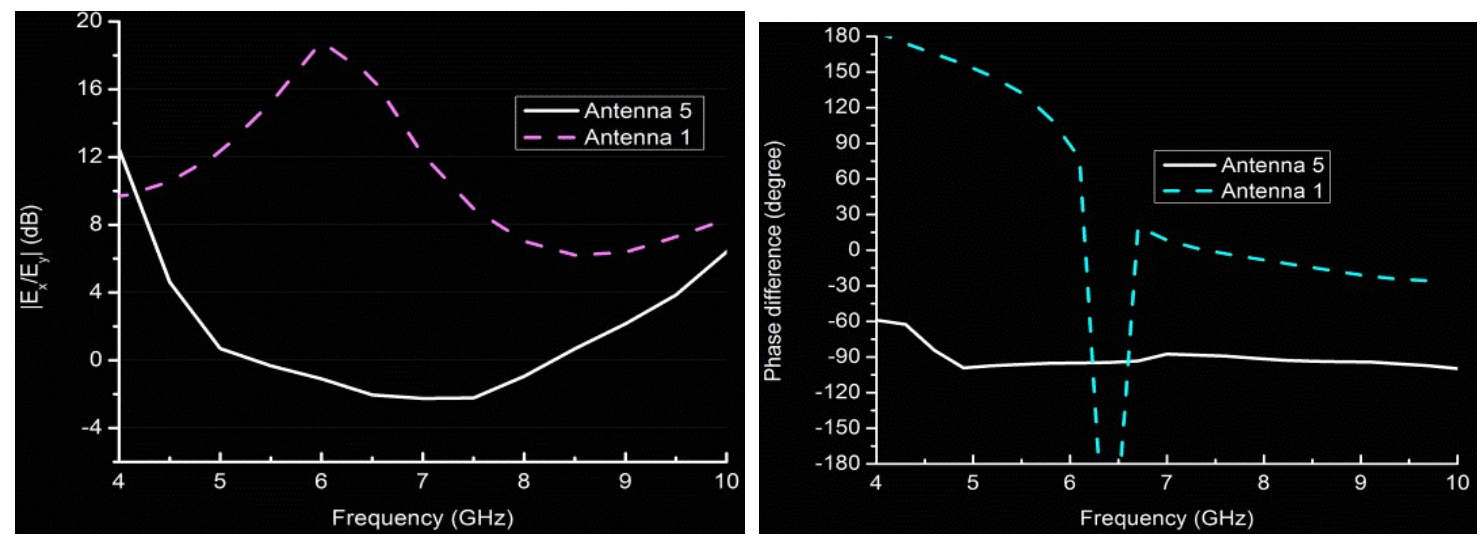

FIG 5. Correlation of the Antenna-1 and Antenna- 5: (a) $\mathbf{j} E x=E y \mathbf{j}$, (b) phase difference. (Left to right fig counting)

An illustration of the current distributions on surface for the presented wearable antenna (at $\mathrm{wt}=270$ degrees, $\mathrm{wt}=180$ degrees, $\mathrm{wt}=0$ degrees, $\& \mathrm{wt}=90$ degrees) is given in Figure 4 . The orthogonal current vectors $\mathrm{A} 1$ and $\mathrm{A} 2$ are symbolized by $\mathrm{A} 1$, and their sum is represented by A2. Figure.4(a) shows that at wt at 0degrees the current density on surface on the upper place of the antenna (A1) 
and the outer-ends of the L-fashioned antenna (A2) raises. The summation (A3) of these 2-vectors is going upward. Fig.4(b) illustrates that at wt=90degrees, the vector sum A3 shifts downward to the right side lower, showing clockwise ratating vectors over a duration.. The sum (A3) also proceeds clockwise in Fig.4(c) and (d) at $\mathrm{wt}=180^{*}$ and 270*, respectively. As a result, the proposed textile antenna can operate in the broadside direction. In Fig.5(a) and (b), we show the $|\mathrm{jEx} / \mathrm{Eyj}|$ and phase difference plots of ANTENNA5 and ANTENNA-1. By introducing the phase difference of 90degrees between the vertical \& horizontal E-field vectors, the L-shaped strip on the ground plane balances the magnitude of both. By etching process a rectangular slot giving the flow of Current that is increased on the ground plane, thus shifting to the left side of the resonating frequency band.

\section{B. MIMO ANTENNA}

Fig.6 shows an antenna configuration with mirrored antenna elements (Ant.5). Microstrip lines of 50 ohms are used to excite the monopole radiators.
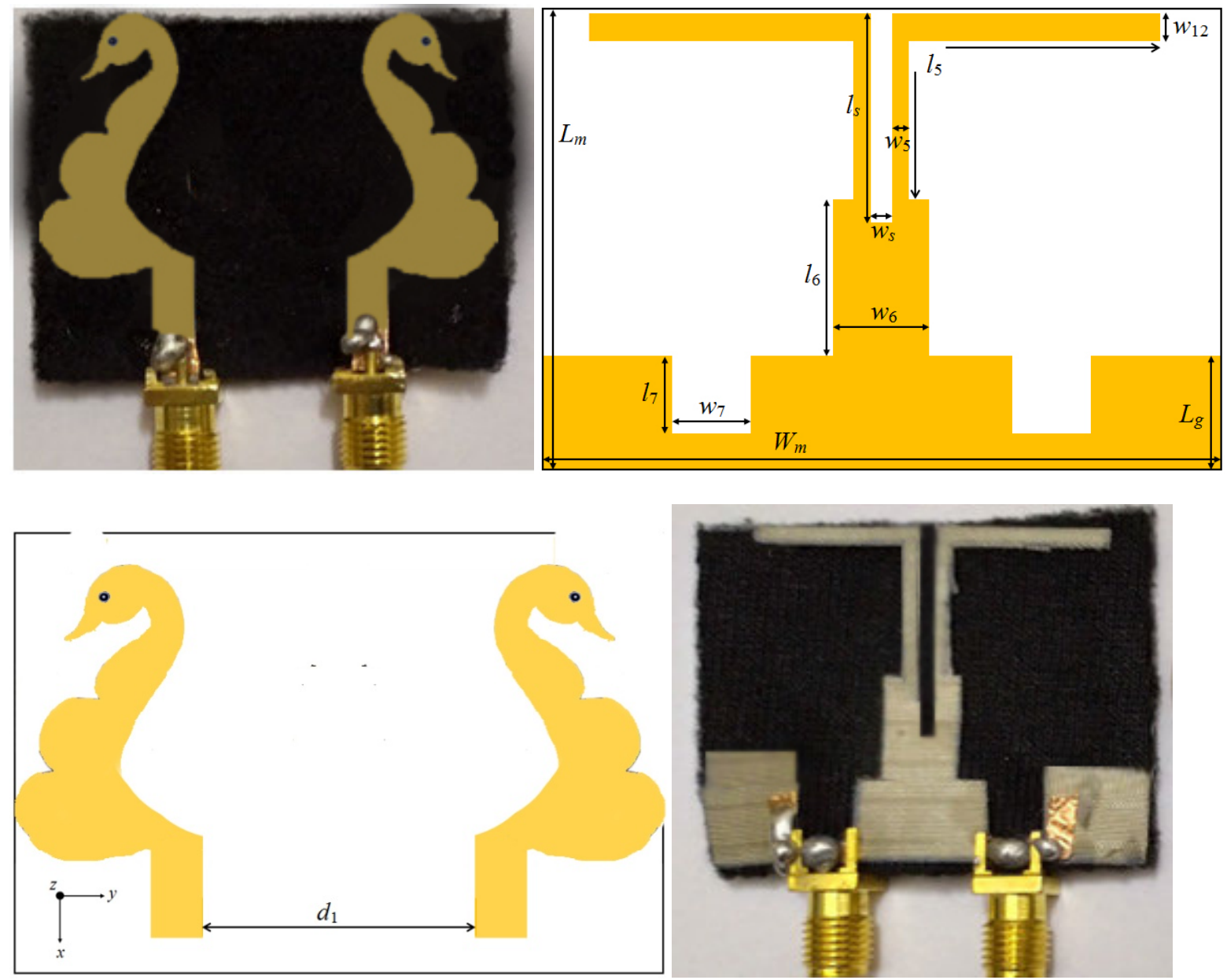

FIG 6. Disclosed Stealth Multple-input-multiple-output antenna: (a) top, (b) back, (c) top views of the fabricated prototype, (d) bottom of the designed specimen.(Left to right fig counting)

Mirrored L-shaped strips are positioned on the back of the wearable substrate to form a common ground. The Disclosed Circularly polarized Multple-input-multiple-output antenna parameters are $\mathrm{Lm}==34.5 \mathrm{~mm}, \mathrm{Wm}=421$ Milli-Meters,Lg=7.62 Milli-Meters,ls=16.45 Milli-Meters,ws=1.0 Milli- 
Meters, 15=27.8 Milli-Meters, w5=1.2 Milli-Meters, 16=9.5 Milli-Meters, w6=6 Milli-Meters, 17=5.7 Milli-Meters, w7=5 Milli-Meters, w12=1.7 Milli-Meters, d1=14.2 Milli-Meters. The proposed textile MIMO antenna measures $42 \times 34.5$ Milli-Meters2. In Fig. 6(c) and (d), we show the bottom \& top views of the textile MIMO antenna prototype.

\section{3) DESIGN PROCESS}

Table 2. MIMO -antenna Simulated results.

\begin{tabular}{|l|l|l|}
\hline & ARBW & S11 \\
\hline Operating Freq(Ghz) & $5.2-7.4$ & $3.4-13.6$ \\
\hline Size(mmxmm) & & $42 \times 32.5$ \\
\hline Thickness of Substrate & & Tan(d) $=0.021, \mathrm{Er}=1.345$ \\
\hline
\end{tabular}

Fig.7(a) shows how the MIMO Antenna A's L-shaped strips are mirrored imaged into a T-shaped body near the middle caused by the Mirrored-Image pattern. The presented MIMO antenna's S12 parameters are stable without any decoupling. As long as there are no decoupling elements between the antenna elements, the proposed Circularly polarized Multple-input-multiple-output radiator has stable S12 parameters. A. and B., respectively, show Fig. 8(a) and (b) the S-parameters and axial ratio curves for the Circularly polarized Multple-input-multiple-output antennas. Antenna elements are separated by a T-shaped stub that offers superior isolation of more than $16 \mathrm{~dB}$.

In spite of this, the antenna's ACBW variations really due to Surface-Wave-Coupling. The MIMO antenna $\mathrm{A}$ is therefore etched with a rectangular slot (size $1 \mathrm{~s}^{*} \mathrm{wsmm} 2$ ) to improve its $3-\mathrm{dB}$ ARBW as shown in Figure 7(b) (Multple-input-multiple-output Ant-B). In addition to improving isolation $(>18.5 \mathrm{~dB})$, the slot would improve MIMO antenna performance. ARBW is realized by optimizing the dimensions of the rectangular slot. Antenna B's simulated impedance bandwidth and ARBW are shown in Table-2.
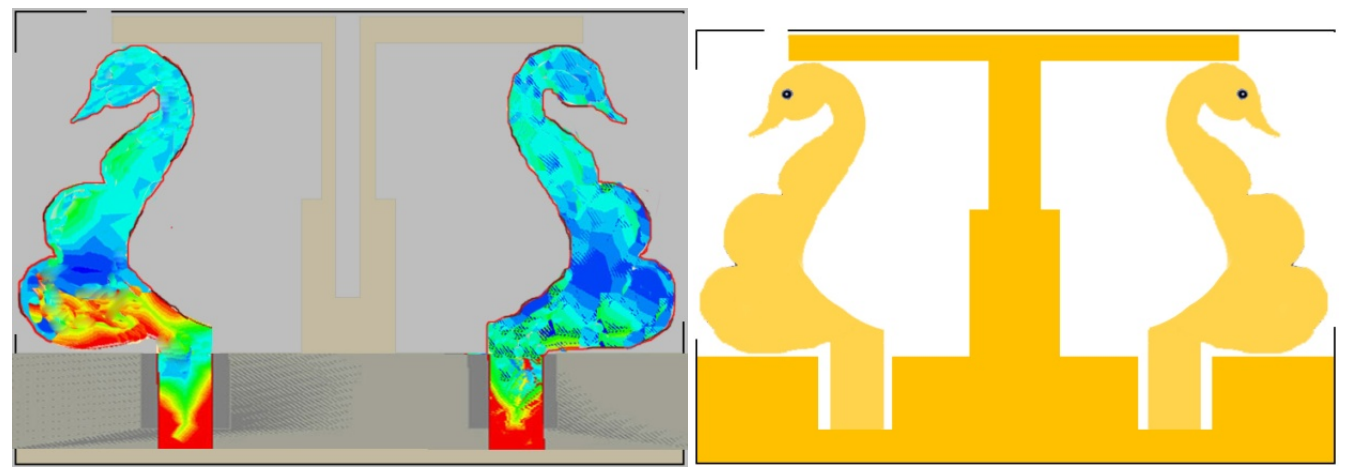

FIG 7. Simulation of: (a) Multple-input-multiple-output AntennaA, (b) Antenna B. (Left to right counting respectively) 

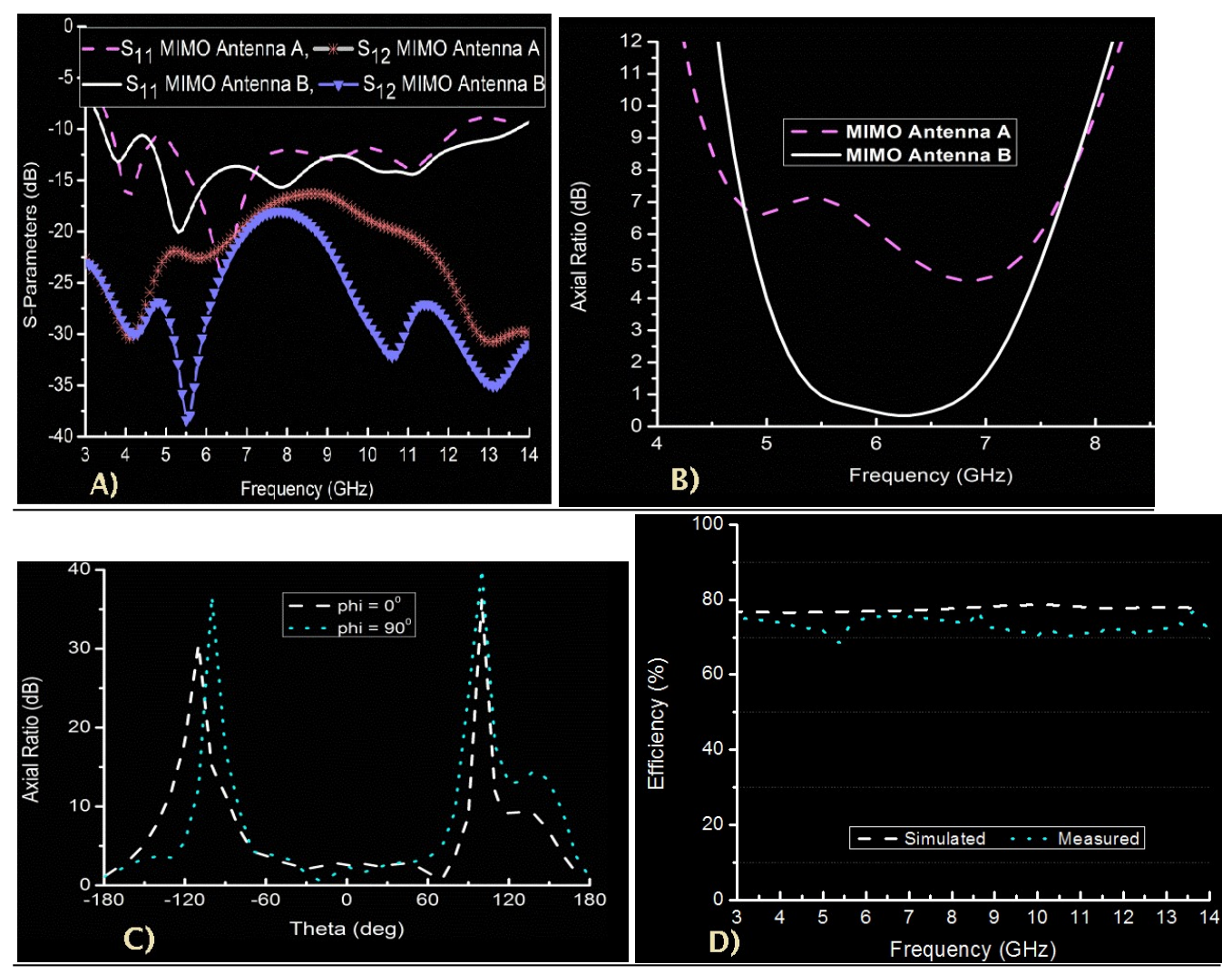

FIG 8. computer-generated response of the Stealth fabric RADIATOR: [A]S-parameters,[B] axial ratio, [C]axial ratio beam-width,[D] antenna efficiency. (Left to right fig counting)

As shown in Figure-8(c), the invented CPMIMO antenna is shown in the flat and oblique directions (phi $=0$ and 90 degrees), with the beam width simulated at $6 \mathrm{GHz}$. The observed $3 \mathrm{~dB}$ ARBW spanning from $\left[-68^{\circ}\right.$ and $\left.-62^{\circ}\right]$ for $\varphi=90^{\circ}$ and from $\left[-63^{\circ} \& 72^{\circ}\right]$ for the $\varphi=0 \circ$. FIG.8 (d) shows both the computer-generated and calculated efficiency for the proposed radiating element, with the highest efficiency at $9.5 \mathrm{GHz}$. Due to the loss-dielectric, mini surface area of the radiator, the efficiency appears to be low.

\section{4) DUAL-SENSE CP PERFORMANCE}

Wearable Circularly polarized Multple-input-multiple-output antenna with dualsense irradiation capability for two ports has been proposed. A diagram of the surface current distribution of the textile antenna is shown in Fig.9 (@wt=0degrees, wt=90degrees, wt=180degrees, and $\mathrm{wt}=270 \mathrm{degrees}$ ). Two orthogonal vectors of current are represented by A1 and A2, while their sum is represented by $\mathrm{A} 3$. 

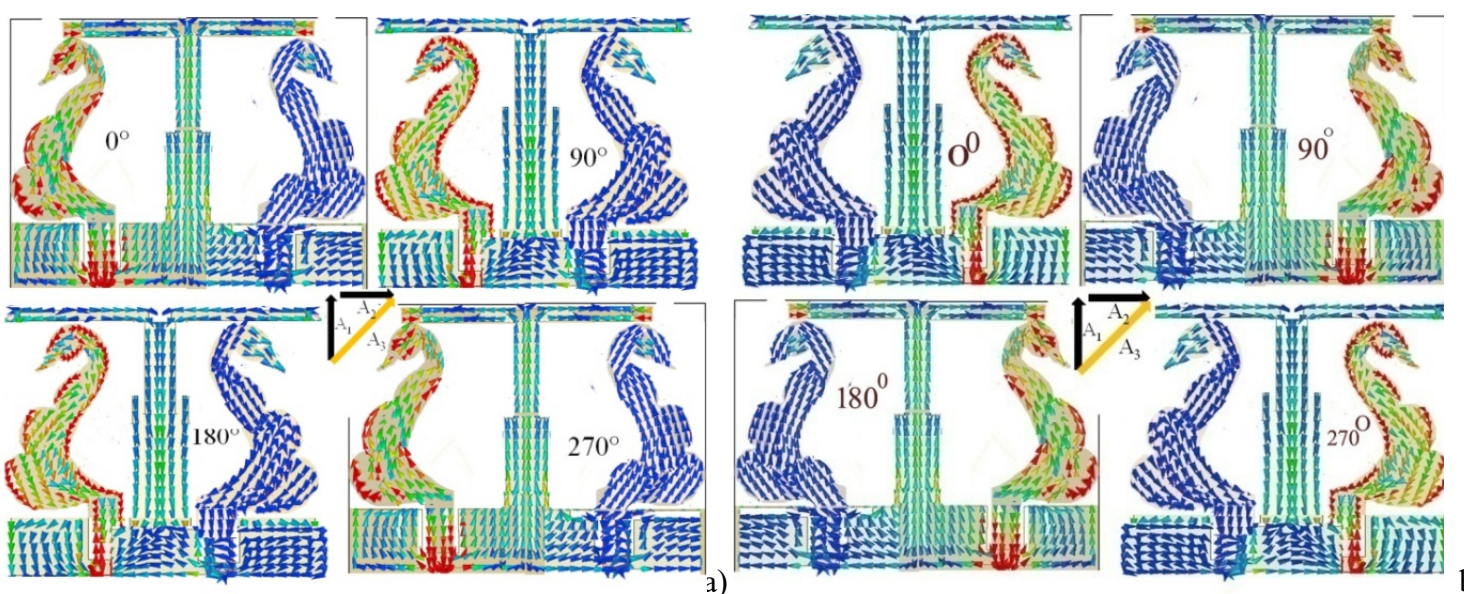

FIG9 . distribution of outside current at 5.25Ghz: (a) port-1 / L.H.C.P Lefthand Circular Plarization, (b) port - 2 / R.H.C.P Right Hand Circular Polarization (Left to right fig counting).

Both Lefthand Circular Plarization(LHCP) or Right Hand Circular Polarization(R.H.C.P) performance can be produced in the broadside direction of the antenna by adjusting the port excitation. In Figures 9(a) and (b), the electric field vectors are illustrated moving clockwise and anticlockwise, respectively.

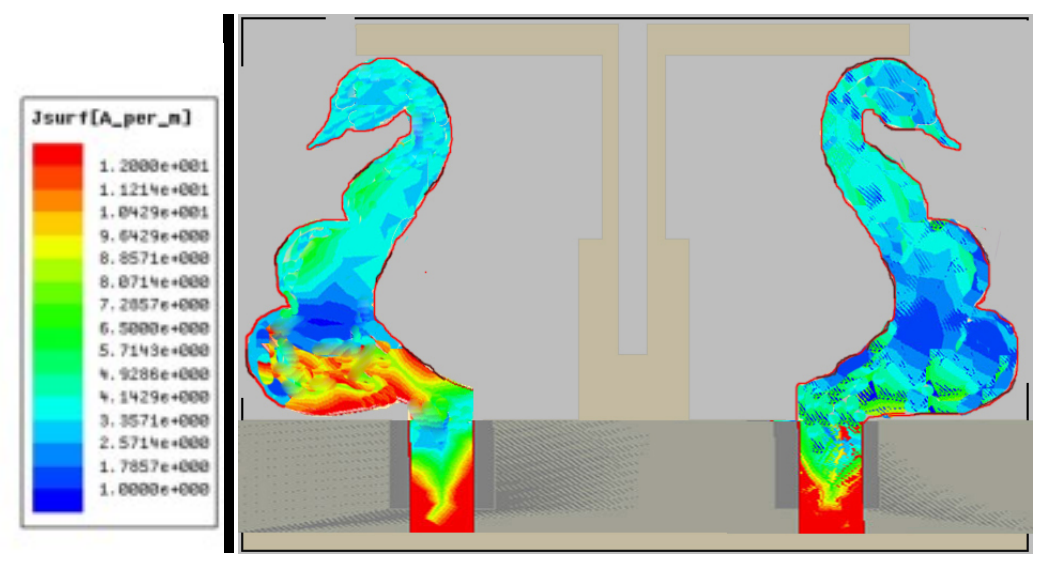

FIG10. computer-generated surface current circulation at $8.49 \mathrm{GigaHz}$

Fig.9(a) shows that the resultant (A3) has been inclined to the upside right at $w t==0$ DEGREES, while the vector addition (A3) has been inclined toward the low-side right at $w t=\Pi / 2$ degrees.In contrast, in Figure.-b, the vector addition (A3) orients itself towards the up-left at $\mathrm{Wt}=$ zero degrees, while the vector addition (A3) is oriented to the low-left at $w t=\Pi / 2^{\circ}$. The load of 50-OHMS is supplied to port-two when port-one is excited, and vice versa. An animated representation of the exterior current circulation of the anticipated Multple-input-multiple-output antenna at 8.5Ghz can be seen in Figure-10. Despite the patch element in the middle, the current circulation is even all the way through the radiator area, validating the antenna gain.

\section{RESULTS DISCUSSION}


A VECTOR - NETWORK - ANALYSE "ANRITSU MS2038CV is utilized to measure the performance of the anticipated wearable "Multple-input-multiple-output antenna". As revealed in Figure.11-), the wearable Multple-Input-Multiple-Output radiator's measured and simulated reflection coefficients. Approximately 113\% (3.6-13 GHz) and $121 \%(3.3-13.6 \mathrm{GHz})$ of the measured and simulated bandwidths exceed $10 \mathrm{~dB}$. According to Figure 11(a), the measured isolation between ports 1 and 2 is GROUND SURPASSING $17 \mathrm{~dB}$, whereas the simulated isolation is over $19 \mathrm{~dB}$. The decoupling structure is designed to operate between 4-6 GHz to minimize coupling at lower frequencies.

In Figure-11-b, the axial ratios of the textile Multple-input-multiple-output antenna are plotted (along the broadside direction). During the simulated waveform period for $5-7.3 \mathrm{GHz}$, the results are $37 \%$ $(5-7.1 \mathrm{GHz})$ and $30 \%(5-7.1 \mathrm{GHz})$. The axial ratio at $5.2 \mathrm{GHz}$ is $1.2 \mathrm{~dB}$ minimum (measured).

A plot of the calculated and computer-generated gain of the anticipated wearable(radiator) antenna can be seen in Figure-11c. At $8.5 \mathrm{GHz}$, the calculated peak gain is $5.69 \mathrm{~dB}$. Antenna measurements and simulations agree well. Because the textile materials and copper part are joined by adhesives, there is a small difference.

\section{B. EMISSION PERFORMANCE(radiation)}

The anticipated CP wearable Multple-input-multiple-output antenna is illustrated with calculated and computer-generated radiation patterns for both $5.25 \mathrm{Ghz} \& 6.3 \mathrm{GHz}$ in Fig. 12. Using a 50-OHMS load on port-2 \& port-1, the MIMO antenna shows LHCP characteristics. MIMO antennas operate in the same manner as RHCP capabilities when port-two is excited and port-one is coordinated to a 50-OHM load. Figures 12(a)-(d) depict the radiation patterns of the proposed double-sense Circularly polarized Multple-input-multiple-output wearable antenna.
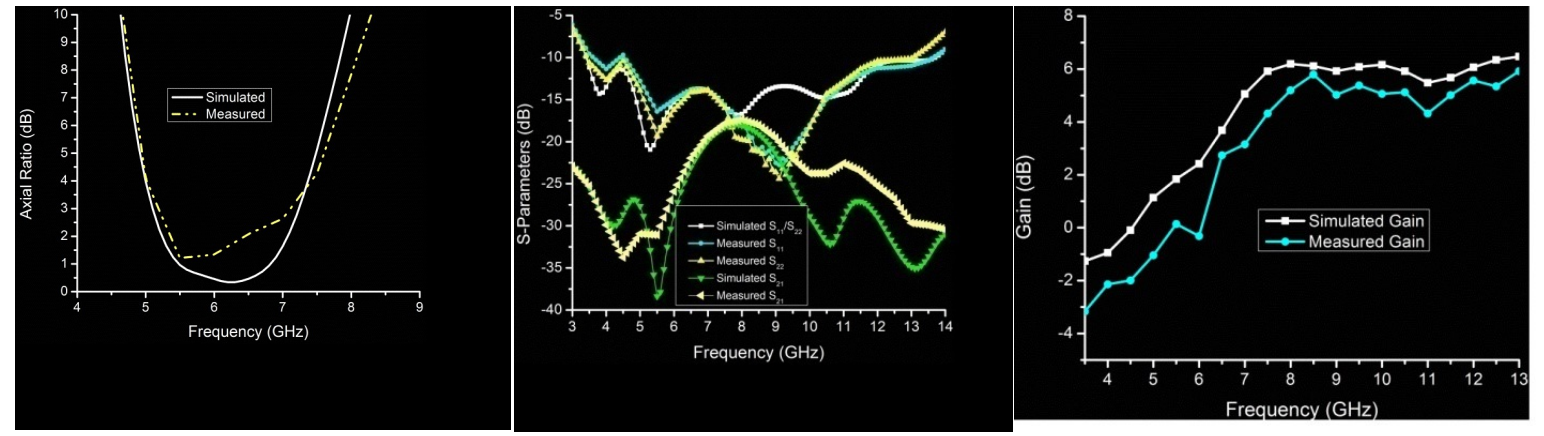

FIG11. software-generated and calculated retort of the proposed Stealth fabric antenna: (a) radiator parameters of , (b)radiator axial ratio, (c) antenna-gain. (Left to right fig counting)

\section{MIMO PERFORMANCE}

As part of the evaluation of the action of the planned wearable antenna diversity system, MIMO parameters like (Coefficient of Envelope. Correlation)ECC, Channel Capacity Loss(C.C.L.), T.A.R.C(Total_Active_Reflection_Coefficient), M.E.G (Mean.Effective-Gain), D.G (Diversity.Gain), and are considered. 

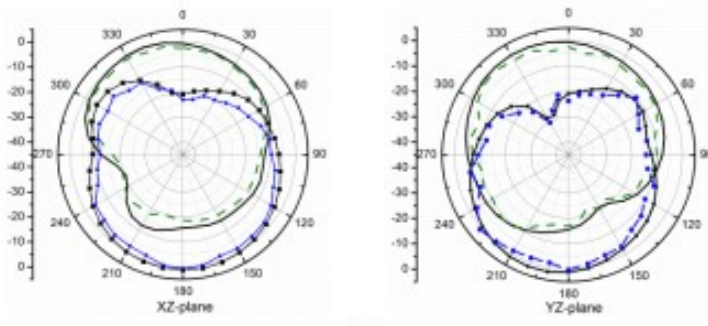

(a)
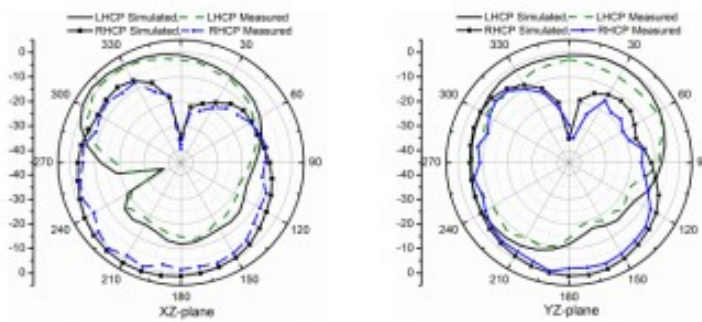

(b)
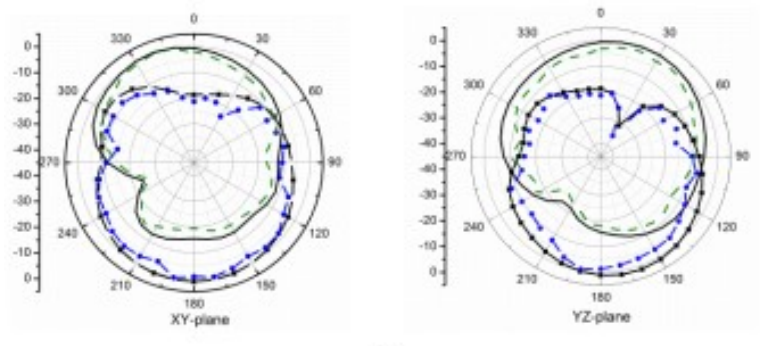

(c)
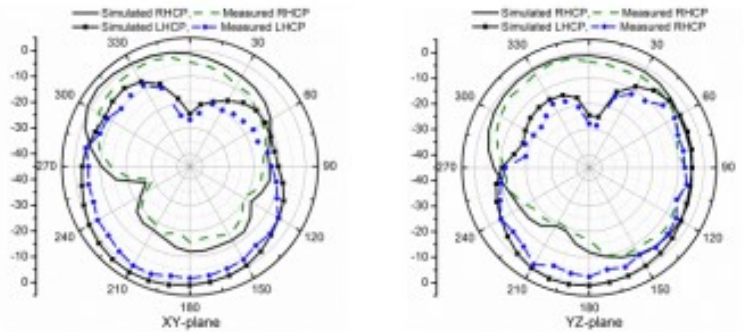

(d)

FIG12. calculated and computer-generated emission patterns of Stealth fabric radiator: (a) 5.25Ghz/port1, (b) 6.32 $\mathrm{GHz} /$ port-1; (c) $5.25 \mathrm{Ghz} /$ port2; (d) $6.2 \mathrm{GHz} /$ port2

Coefficient of Envelope Correlation (E.C.C) $<0.5$, Gain-Diversity (D.G) $>9.95$,TARC $<0 \mathrm{~dB}$, ChannelCapacity-Loss $(\mathrm{CCL})<0.4 \mathrm{bits} / \mathrm{sec} / \mathrm{Hertz}$, and MEG ratio amid 0 and $-3 \mathrm{~dB}$ are compulsory for efficient Multple-input-multiple-output antenna operation [22-to-25].
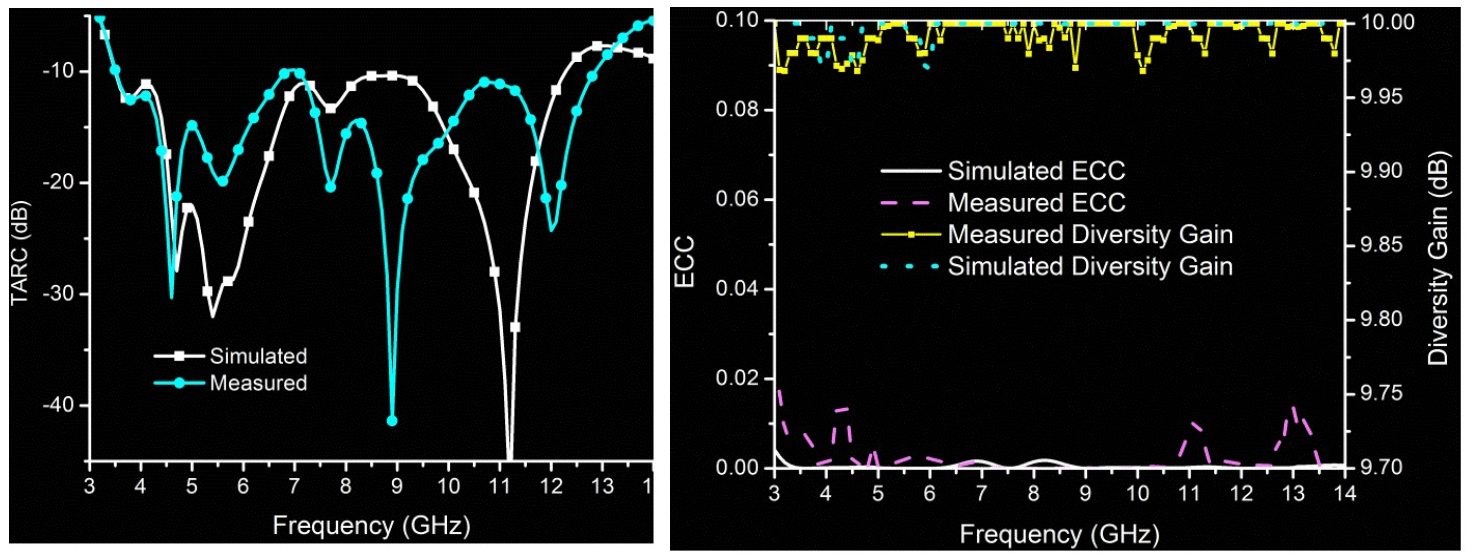

FIG13. Diversity performance of the Stealth fabric Multple-input-multiple-output antenna: (a) E.C.C and D.G, (b)

T.A.R.C. (Left to right fig counting)

\section{1) Envelope Correlation Coefficient (ECC) \& Diversity Gain (DG)}

E.C.C helps develop correlations between antenna ports in MIMO systems. Evaluation of the E.C.C [25] can be achieved using the following relation.

$$
\mathrm{ECC}=\frac{\left|S_{11}^{*} S_{12}+S_{21}^{*} S_{22}\right|}{\left(1-\left|S_{11}\right|^{2}-\left|S_{21}\right|^{2}\right)\left(1-\left|S_{22}\right|^{2}-\left|S_{12}\right|^{2}\right)}
$$


Fig. 13(a) illustrates the computer-generated and calculated ENVELOPE CORRELATION COEFFICIENT (ECC) graphs for the presented textile Multple-input-multiple-output antenna. There is a difference in ENVELOPE CORRELATION COEFFICIENT (E.C.C) among radiatorss-1 and -2 of $<0.02$. The BELOW relation may be used to calculate another important MIMO parameter, DIVERSITY GAIN (DG).

$$
\mathrm{DG}=10 \sqrt{1-\mathrm{ECC}^{2}}
$$

Fig. 13(a) contains simulations and measurements of the anticipated Multple-input-multiple-output textile antenna. The DIVERSITY-GAIN (D.G) exceeds $9.96 \mathrm{~dB}$ in the case of the textile antenna.

\section{2) TARC}

Multi-port antenna elements can interfere with each other's performance when they operate simultaneously. This effect is considered by TARC, which is presented as the $\frac{\sqrt{\text { intensity of insident signals }}}{\text { reflected signals }}$ A TOTAL ACTIVE REFLECTIVE COEFFICIENT (TARC)may be calculated based on the following equation [26] for the proposed two-port MIMO antenna.

$$
\operatorname{TARC}=\frac{\sqrt{\left(S_{11}+S_{22}\right)^{2}+\left(S_{21}+S_{12}\right)^{2}}}{\sqrt{2}}
$$
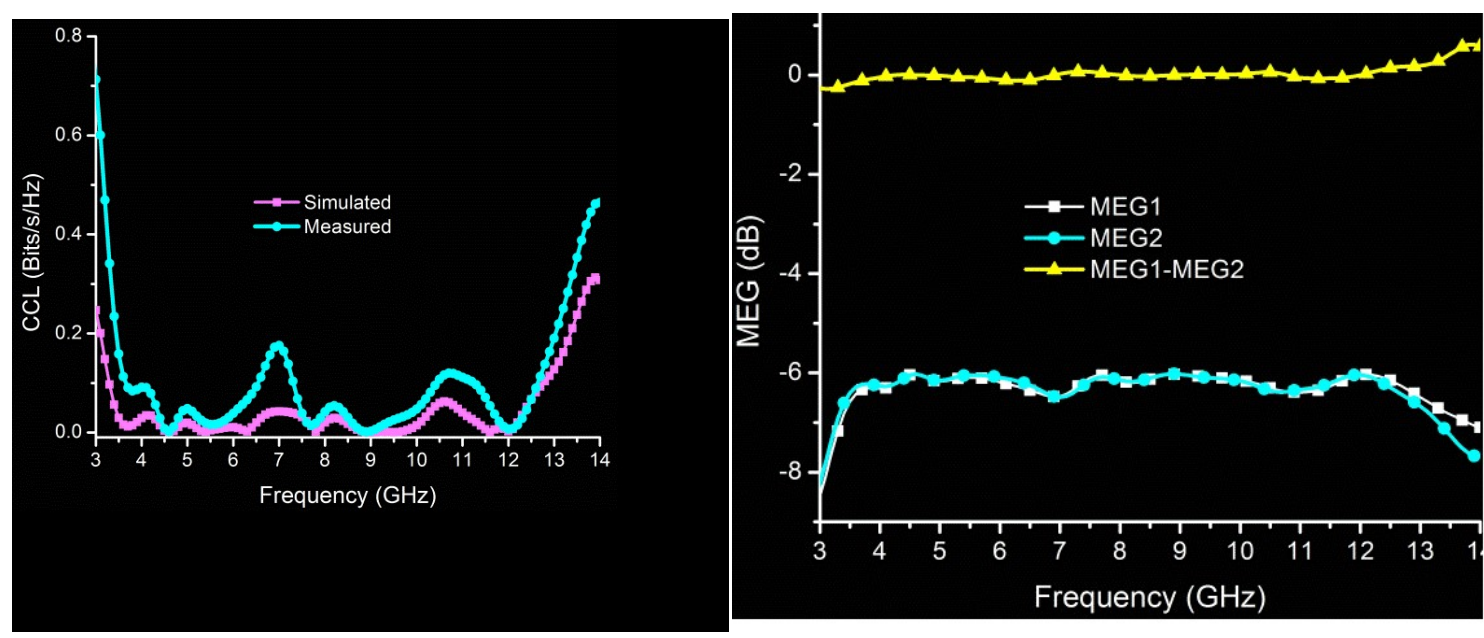

FIG14. Anticipated Stealth fabric Multple-input-multiple-output antenna: (a) CHANNEL CAPACITY LOSS(C.C.L), (b) M.E.G. (Left to right fig counting)

The simulated and measured curves of the TOTAL ACTIVE REFLECTIVE COEFFICIENT (TARC)are shown in Figure 13(b). The measurement and simulation TOTAL ACTIVE REFLECTIVE COEFFICIENT (T.A.R.C)values here are less than -10Deibles across the whole working band.

\section{3) Channel Capacity Loss(C.C.L) \& M.E.G:}


Message transmission rate can be measured by evaluating the ChannelCapacityLoss(C.C.L) for a communication channel, \& the Channel Capacity Loss(CCL) can be calculated as [25].

$$
C(\text { loss })=-\log _{2} \operatorname{det}\left(\beta^{R}\right)
$$

where

$$
\begin{aligned}
& \beta^{R}=\left[\begin{array}{ll}
R_{11} & R_{12} \\
R_{21} & R_{22}
\end{array}\right], \quad R_{i i}=1-\left(\left|S_{11}\right|^{2}+\left|S_{22}\right|^{2}\right) \text { and } \\
& R_{i j}=-\left(S_{i i}^{*} S_{i j}+S_{j i}^{*} S_{i j}\right) \quad \text { for } i, j=1 \text { or } 2
\end{aligned}
$$

In Figure 14.(a), the proposed textile MIMO antenna's measured and simulated "ChannelCapacityLoss-C.C.L" curves are shown. The Channel Capacity Loss(CCL) values for the entire operating band are below $0.2 \mathrm{~b} / \mathrm{s} / \mathrm{Hz}$.

An MIMO antenna's gain is reflected by the MEG.

$$
\begin{aligned}
& M E G_{1}=0.5 \eta_{1, \text { rad }}=0.5\left[1-\left|S_{11}\right|^{2}-\left|S_{12}\right|^{2}\right] \\
& M E G_{2}=0.5 \eta_{2, \text { rad }}=0.5\left[1-\left|S_{12}\right|^{2}-\left|S_{22}\right|^{2}\right]
\end{aligned}
$$

The study illustrates how the wireless environment impacts diversity. The MEG [22] can be premeditated using the subsequent equations.
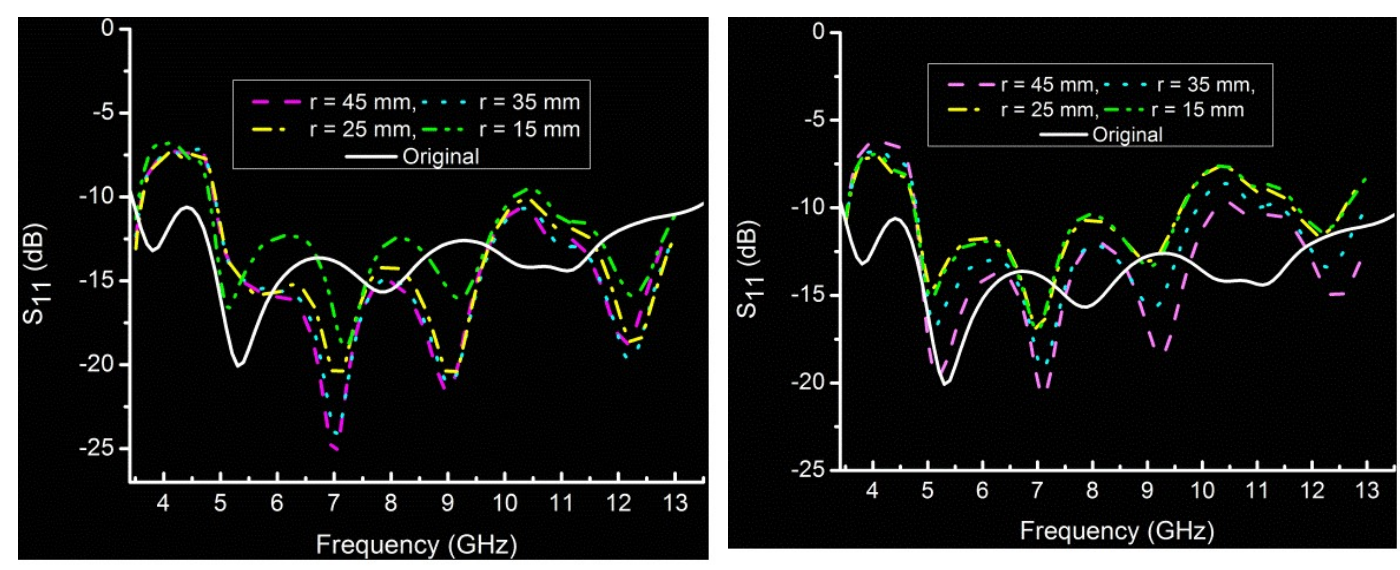

FIG15. $\mathrm{S}_{11}$ contrast for diverse bending radii: E-plane, and H-plane. ( Left to right fig counting).

\section{BENDING EFFECT ANALYSIS}

If worn in clothing on human body parts like the arms and thighs, the wearable antenna can bend. We ran simulations of the antenna at different radii to ensure its structural integrity, including 15 MilliMeters, 25 MilliMeters, 35 MilliMeters, and 45 MilliMeters. Table 15 and Table 16 illustrate the results from a simulated S11 antenna and an axial ratio for diverse winding radii. To facilitate 
analyze MIMO antennas, bending of the antenna for both the E-plus the H-plane are analyzed. A simulation for the bending of the original antenna, compared with that of the simulated results presented in Figures 15(a) and (b). By comparing the results with the original results, it can be seen that the curves tend to lean to the elevated frequency side by roughly $710 \mathrm{MHz}$ 's .

Table 3. MIMO antenna diversity performance for various bending radii

\begin{tabular}{|l|l|l|l|l|l|}
\hline $\begin{array}{l}\text { Bending } \\
\text { Rad(MilliMeter }\end{array}$ & \multicolumn{4}{l|}{ Parameter } \\
\cline { 2 - 6 } & $\begin{array}{l}\text { E.C. } \\
\text { C }\end{array}$ & $\begin{array}{l}\text { D.G(deciBells } \\
\text { M.E.G.1- } \\
\text { M.E.G.2(dB } \\
)\end{array}$ & $\begin{array}{l}\text { T.A.R.C(dB } \\
\text { CHANNEL CAPACITY }\end{array}$ & $\begin{array}{l}\text { CHASS(C.C.L)(bits/ssec/Hert } \\
\text { LOS) } \\
\text { z) }\end{array}$ \\
\hline 46 & 0.022 & 9.96 & $+/-0.5$ & -10 & 0.21 \\
\hline 30 & 0.023 & 9.96 & $+/$ & -10 & 0.22 \\
\hline 20 & 0.024 & 9.94 & $+/$ & -9.5 & 0.23 \\
\hline 10 & 0.024 & 9.92 & $+/$ & -9.8 & 0.23 \\
\hline
\end{tabular}

The Multple-input-multiple-output radiator performs best at several bending circumstances, exhibiting both an equal bandwidth and an excellent S11 result; however, the results deteriorate as the bend radius decreases because of an unbalanced impedance between the feed line and the port. Similar results are also observed in bending analyses in the Horizontal-plane $(\mathrm{H})$, where the resonating band shifts right as the bending radius decreases.

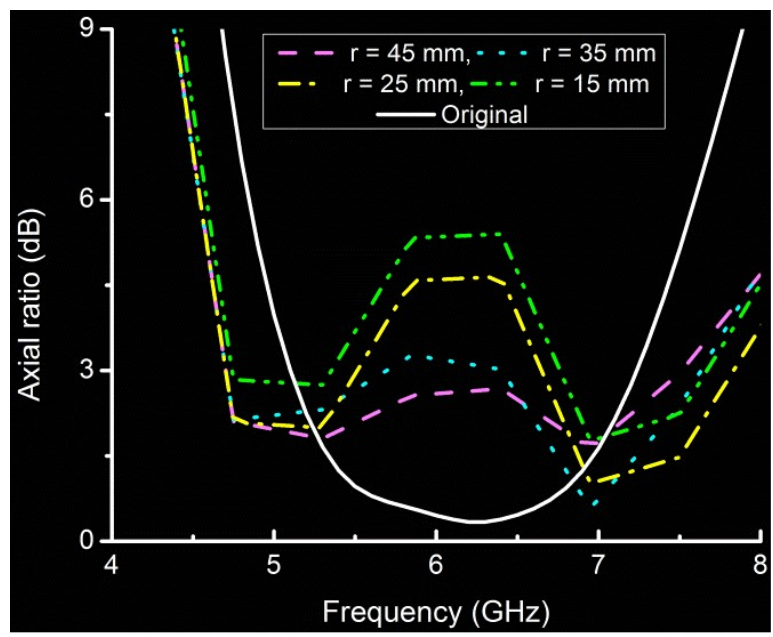

FIG16. Axial ratio evaluation for diverse bending radii in the (E) plane.

An antenna bending model simulating the axial ratio, shown in Fig. 16, the radius changing between 16 MilliMeters and 46 MilliMeters is illustrated. At $6 \mathrm{GHz}$, the 3-dB ARBW degrades owing to the feed line offset, shifting to the down-ward as the bending radius grows.AxialRatio and S11 of the anticipated wearable radiator in the (E)plane have been measured in Fig.17(a\&b), with nice conformity amid the computer-generated and calculated outcome. 

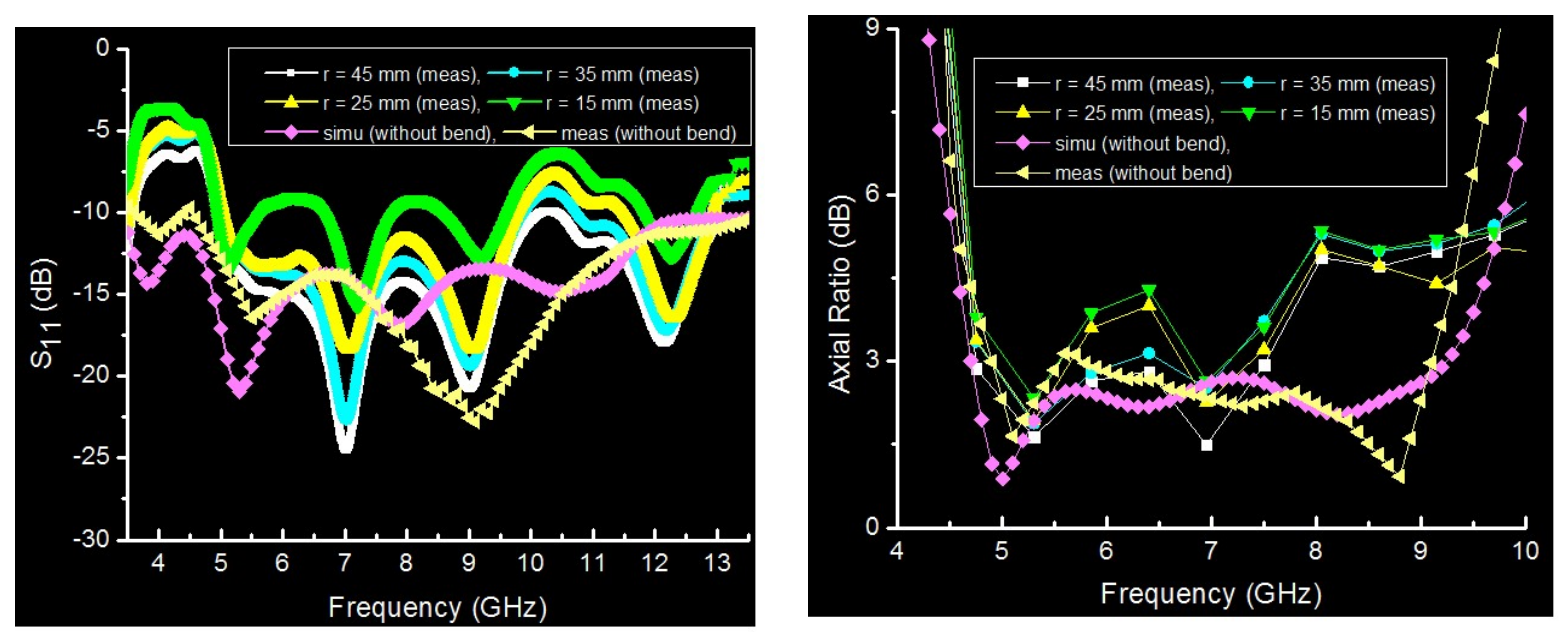

FIG17. Performance contrast for diverse bending radii in the (E)plane: S11,AXIAL-RATIO. (Left to right fig counting)

Table 3 shows performance parameters for the MIMO antenna when bent in various bending situations, including, Total.Active.Reflective.Coefficient(T.A.R.C), Diversity.Gain(D.G), , Envelope.Correlation.Coefficient(.E.C.C), M.E.G and Channel Capacity Loss(.C.C.L.). Due to variations in the current delivery on the ground plane of the antenna, the performance of the radiator decreases as the bending radii grows.

Additionally, the antenna on the body is analyzed. The 4-level human being arm revealed in Figure18a has fundamental values of density, conductivity, and LossTangent permittivity as shown in Table 4.

Table 5. Fundamental properties of "human being" body tissue at 5.78Gigahertz

\begin{tabular}{|l|l|l|l|l|}
\hline Property/Tissue & Muscle & Bone & Fat & Skin \\
\hline Permittivity & 48.48 & 10.3 & 4.95 & 35.1 \\
\hline Conductivity & 4.96 & 4.56 & 0.29 & 3.71 \\
\hline LossTangent & 0.24191 & 0.25244 & 0.19382 & 0.2835 \\
\hline Density & 1060 & 1850 & 910 & 1100 \\
\hline
\end{tabular}

As can be seen in Fig.18(b), the simulated S11 results for different bending radii are moved to the right, due to the loss character of the human arm and the reduced length of the current path.

\section{S.A.R CHARACTERISTICS (Specific-Absorption-Rate)}

This relation [27] can be utilized to define the SAR value as follows.

$$
\mathrm{SAR}=\frac{d}{d t}\left(\frac{d E}{d m}\right)=\frac{d}{d t}\left(\frac{d E}{\rho \cdot d A}\right)(W / K g)
$$

The incremental mass is $\mathrm{dm}$, the incremental energy is $\mathrm{dE}$, and the volume element is $\mathrm{dA}$. Based on the calculation of the antenna's maximum input power, $367.86 \mathrm{~mW}$ is the maximum power for 10 
grams of tissue at 2 Watts input powers, exceeding the highest standard limit. Accordingly, the anticipated radiator(CPMIMO) can work within its acceptable boundaries.

Table 5. Correlation of the anticipated(Presented) stealth wearable antenna with the existing wearable antennas(MIMO)

\begin{tabular}{|l|l|l|l|l|l|l|l|l|}
\hline Ref & $\begin{array}{l}\text { Antenna } \\
\text { Size(mm2) }\end{array}$ & Gain(dB) & $\begin{array}{l}\text { Operating } \\
\text { BW(Ghz) }\end{array}$ & Substrate(Er) & $\begin{array}{l}\text { Fractional } \\
\text { Bw(\%) }\end{array}$ & ARBW(Ghz) & $\begin{array}{l}\text { Dual } \\
\text { Sense }\end{array}$ & Isolation \\
\hline$[11]$ & $40 * 40$ & 2.36 & $1.6-3.8$ & FR-4(1.6) & 92.08 & $1.8-3.1$ & No & $>24$ \\
\hline$[12]$ & $92.3 * 101.6$ & 5.8 & $\begin{array}{l}2.367- \\
2.53,5.14- \\
5.86\end{array}$ & Textile(1.3) & $6.65-13.09$ & --- & No & $>20$ \\
& & & & & & & \\
\hline$[13]$ & Pi(21.1)2 & 4.2 & $2.4-2.49$ & FR-4(1.6) & 3.68 & -- & No & $>15$ \\
\hline$[14]$ & $38.1 * 38.1$ & 2.79 & $2.3-2.8$ & Textile(1.2) & 19.6 & -- & No & $>12$ \\
\hline$[15]$ & $55 * 35$ & 6.9 & $2.64-12.28$ & Jeans(1.6) & 129.22 & -- & No & $>26$ \\
\hline$[16]$ & $70 * 40$ & 4.4 & $2.4-8$ & Jeans(1.6) & 107.69 & -- & No & $>22$ \\
\hline$[17]$ & $60 * 60$ & 4 & $2.0-4.76$ & FR-4(1.6) & 81.65 & $2.0-3.7$ & Yes & $>15$ \\
\hline$[18]$ & $32 * 32$ & 3.8 & $1.4-8.73$ & FR-4(1.6) & 144.71 & $3.74-8.8$ & Yes & $>20$ \\
\hline $\begin{array}{l}\text { Proposed } \\
\text { Antenna }\end{array}$ & $42 * 34.5$ & 5.7 & $3.6-13$ & Textile(1.34) & 113.25 & $5.2-71$ & Yes & $>18$ \\
\hline
\end{tabular}

An analysis of textile MIMO antennas and recent textile wearable antennas is shown in Table5. These parameters such as substrate material, antenna size, ARBW, operating bandwidth, sense of polarization, fractional bandwidth, gain, and isolation are compared. In [12]-[16], wearable antennas were presented as LPAs. Circular polarization showed in [11], while [17]-[21] were dual-sense CP antennas, but their operating bandwidth was small. Circular polarization showed in [11], while [17][21] were dual-sense CP antennas, but their operating bandwidth was small. The proposed textile antenna has a smaller size and axial ratio than the reported antennas and has a dual-sense (Left hand circular polarization L.H.C.P /Right hand circular polarization R.H.C.P) design.
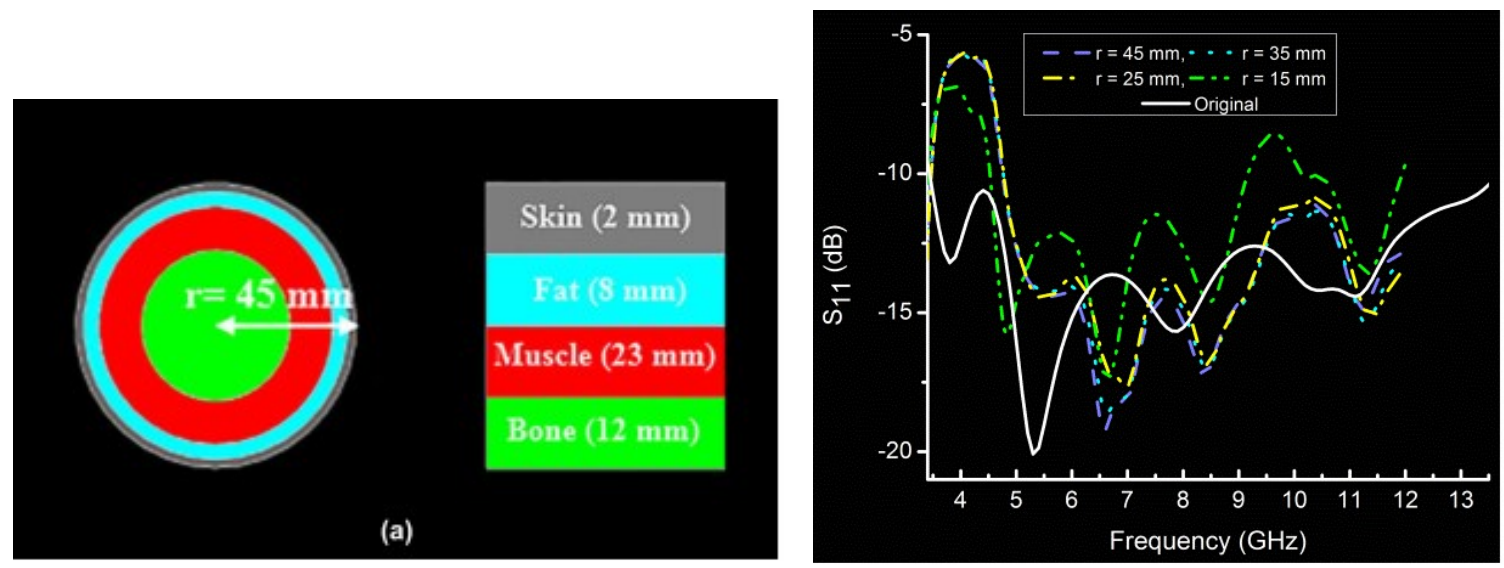

FIG18. On-body action of the proposed CPMIMO antenna: (a) 4-level layer tissue speimen, (b) S11 contrast for various bending radii in the (E)plane. (Left to right fig counting)

\section{CONCLUSION}

A II-port stealth CP wearable Multple-Input-Multiple-Output radiator for Circularly polarized wideband operation is proposed in this paper. An overall size of $34.5 \mathrm{X} 42 \mathrm{X} 1 \mathrm{~mm} 3 \mathrm{can}$ be found on 
the textile antenna. ARBW and impedance bandwidth of $113 \%$ are observed in the anticipated Multple-Input-Multiple-Output antenna. DIVERSITY.GAIN (D.G) is greater than the value 9.96dB, Envelope.Correlation.Coefficient-E.C.C below the value 0.0200, and Channel Capacity Loss(CCL) slightly below the value $0.2 \mathrm{~b} / \mathrm{s} / \mathrm{Hz}$ are displayed on the antenna. Without any additional decoupling elements, the isolation obtained exceeds $18 \mathrm{~dB}$. Human tissue models are also used to analyze SAR of the presented radiator, which is found to be within the allowed range of frequencies. This radiator is best usable for C-band up-link and down-link applications in wireless networks on and off the body, including WLAN, Bluetooth, and WiMAX.
ABBRIVATIONS:
1 C.P = Circularly Polarized
2. M.I.M.O = multiple-input-output
3. T.A.R.C = Total Active-Reflective-Coefficient
4. UWB = Ultra Wide Band
5. A.R.B.W = Axial Ratio Band-Width
6. C.C.L =Channel-Capacity-Loss about
7. E.C.C = Envelope-Correlation-Coefficient
8 M.E.G =Mean-Effective-Gain
9 D.G = DiversityGain
10. S.A.R = Specific-Absorption-Rate
11. W-LAN = Wireless Local Area Network
12. D.G.S =defected-ground-structure
13. R.H.C.P $=$ Right Hand Circular Polarization

14. L.H.C.P = Left Hand Circular Polarization

\section{REFERENCES}

[1] Y. S. Chen and T.-Y. Ku, "A low-profile wearable antenna using a minia-ture high impedance surface for smartwatch applications," IEEE Antennas Wireless Propag. Lett., vol. 15, pp. 1144-1147, 2016.

[2] R. Salvado, C. Loss, R. Gonçalves, and P. Pinho, "Textile materials for the design of wearable antennas: A survey," Sensors, vol. 12, no. 11,pp. 15841-15857, 2012.

[3] P. Nepa and H. Rogier, "Wearable antennas for off-body radio links at VHF and UHF bands: 
Challenges, the state of the art, and future trends below $1 \mathrm{GHz}$," IEEE Antennas Propag. Mag., vol. 57, no. 5, pp. 30-52, 2015.

[4] B. Hu, G.-P. Gao, L.-L. He, X.-D. Cong, and J.-N. Zhao, "Bending and on-arm effects on a wearable antenna for $2.45 \mathrm{GHz}$ body area network," IEEE Antennas Wireless Propag. Lett., vol. 15, pp. 378-381, 2016.

[5] K. N. Paracha, S. K. A. Rahim, P. J. Soh, and M. Khalily, "Wear-able antennas: A review of materials, structures, and innovative fea- tures for autonomous communication and sensing," IEEE Access, vol. 7, pp. 56694-56712, 2019.

[6] M. Klemm, I. Locher, and G. Tröster, "A novel circularly polarized textile antenna for wearable applications," Proc. 7th Eur. Conf. Wireless Technol.,2004, pp. 137-140.

[7] Z. H. Jiang, Z. Cui, T. Yue, Y. Zhu, and D. H. Werner, "Compact, highly efficient, and fully flexible circularly polarized antenna enabled by silver nanowires for wireless body-area networks,'” IEEE Trans. Biomed. Circuits Syst, vol. 11, no. 4, pp. 920-932, Aug. 2017.

[8] Z. H. Jiang and D. H. Werner, "A compact, wideband circularly polarized co-designed filtering antenna and its application for wearable devices with low SAR," IEEE Trans. Antennas Propag., vol. 63, no. 9, pp. 3808-3818, Sep. 2015.

[9] F. A. Dicandia, S. Genovesi, and A. Monorchio, "Analysis of the perfor- mance enhancement of MIMO systems employing circular polarization," IEEE Trans. Antennas Propag., vol. 65, no. 9, pp. 4824-4835, Sep. 2017.

[10] H. Li, J. Xiong, Z. Ying, and S. L. He, "Compact and low profile co- located MIMO antenna structure with polarisation diversity and high port isolation," Electron. Lett., vol. 46, no. 2, pp. 108-110, 2010.

[11] A. Iqbal, A. Smida, A. J. Alazemi, M. I. Waly, N. K. Mallat, and S. Kim, "'Wideband circularly polarized MIMO antenna for high data wearable biotelemetric devices," IEEE Access, vol. 8, pp. 17935-17944, 2020.

[12] S. Yan, P. J. Soh, and G. A. E. Vandenbosch, "Dual-band textile MIMO antenna based on substrate-integrated waveguide (SIW) technol- ogy," IEEE Trans. Antennas Propag., vol. 63, no. 11, pp. 4640-4647, Nov. 2015.

[13] D. Wen, Y. Hao, M. O. Munoz, H. Wang, and H. Zhou, "A compactand low-profile MIMO antenna using a miniature circular high-impedance surface for wearable applications," IEEE Trans. Antennas Propag., vol. 66, no. 1, pp. 96-104, Jan. 2018.

[14] H. Li, S. Sun, B. Wang, and F. Wu, "Design of compact single-layer textile MIMO antenna for wearable applications," IEEE Trans. Antennas Propag., vol. 66, no. 6, pp. 3136-3141, Jun. 2018.

[15] A. K. Biswas and U. Chakraborty, "Compact wearable MIMO antenna with improved port isolation for ultra-wideband applications,' IET Microw., Antennas Propag., vol. 13, no. 4, pp. 498-504, Mar. 2019.

[16] A. K. Biswas and U. Chakraborty, "A compact wide band textile MIMO antenna with very low mutual coupling for wearable applications," Int. J. RF Microw. Comput.-Aided Eng., vol. 29, no. 8, Aug. 2019, Art. no. e21769.

[17] R. K. Saini and S. Dwari, “A broadband dual circularly polarized square slot antenna," IEEE Trans. Antennas Propag., vol. 64, no. 1, pp. 290-294, Jan. 2016.

[18] D. S. Chandu and S. S. Karthikeyan, "A novel broadband dual circu- larly polarized microstrip-fed monopole antenna," IEEE Trans. Antennas Propag., vol. 65, no. 3, pp. 14101415, Mar. 2017.

[19] M. Y. Jamal, M. Li, and K. L. Yeung, “Isolation enhancement of closely packed dual circularly polarized MIMO antenna using hybrid technique,' IEEE Access, vol. 8, pp. 11241-11247, 2020. 
[20] U. Ullah, I. B. Mabrouk, and S. Koziel, "Enhanced-performance circu- larly polarized MIMO antenna with polarization/pattern diversity,"' IEEE Access, vol. 8, pp. 11887-11895, 2020.

[21] L. Qu, H. Piao, Y. Qu, H.-H. Kim, and H. Kim, “Circularly polarised MIMO ground radiation antennas for wearable devices," Electron. Lett., vol. 54, no. 4, pp. 189-190, 2018.

[22] J. Nasir, M. H. Jamaluddin, M. Khalily, M. R. Kamarudin, I. Ullah, and

R. Selvaraju, "A reduced size dual port MIMO DRA with high isolation for 4G applications," Int. J. RF Microw. Comput.-Aided Eng., vol. 25, no. 6, pp. 495-501, 2015.

[23] S. H. Chae, S.-K. Oh, and S.-O. Park, "Analysis of mutual coupling, correlations, and TOTAL ACTIVE REFLECTIVE COEFFICIENT (TARC)in WiBro MIMO array antenna,' IEEE Antennas Wireless Propag. Lett., vol. 6, pp. 122-125, 2007.

[24] H. S. Singh, G. K. Pandey, P. K. Bharti, and M. K. Meshram, "Design and performance investigation of a low profile MIMO/diversity antenna for WLAN/WiMAX/HIPERLAN applications with high isolation," Int. J. RF Microw. Comput.-Aided Eng., vol. 25, no. 6, pp. 510-521, Aug. 2015.

[25] Y. K. Choukiker, S. K. Sharma, and S. K. Behera, "Hybrid fractal shape planar monopole antenna covering multiband wireless communications with MIMO implementation for handheld mobile devices," IEEE Trans. Antennas Propag., vol. 62, no. 3, pp. 1483-1488, Mar. 2014.

[26] S. I. Jafri, R. Saleem, M. F. Shafique, and A. K. Brown, "Compact reconfigurable multiple-input-multiple-output antenna for ultra wideband applications," IET Microw., Antennas Propag., vol. 10, no. 4, pp. 413-419, Mar. 2016.

[27] IEEE Recommended Practice for Measurements and Computations of Radio Frequency Electromagnetic Fields With Respect to Human Exposure to Such Fields, $100 \mathrm{kHz}$ to $300 \mathrm{GHz}$, IEEE Standard C95.3-2002, 2002.

[28] W. H. Bailey, R. Bodemann, J. Bushberg, C.-K. Chou, R. Cleveland,A. Faraone, K. R. Foster, K. E. Gettman, K. Graf, T. Harrington, and A. Hirata, "Synopsis of IEEE Std C95.1TM -2019 'IEEE standard for safety levels with respect to human exposure to electric, magnetic, and electromagnetic fields, $0 \mathrm{~Hz}$ to $300 \mathrm{GHz}$, '” IEEE Access, vol. 7, pp. 171346-171356, 2019.

[29] A. Hirata and S. Kodera, "Difference of ICNIRP guidelines and IEEE C95.1 standard for human protection from radio-frequency exposures," in Proc. Int. Symp. Electromagn. Compat., EMC Eur., Rome, Italy, Sep. 2020,pp. 1-5.

[30] International Commission on Non-Ionizing Radiation Protection, "Guide- lines for limiting exposure to electromagnetic fields (100 kHz to $300 \mathrm{GHz})$,' Health Phys., vol. 118, no. 5, pp. 483-524, 2020.

[31] S. Kumar et al., "Wideband Circularly Polarized Textile MIMO Antenna for Wearable Applications," in IEEE Access, vol. 9, pp. 108601-108613, 2021, doi: 10.1109/ACCESS.2021.3101441.

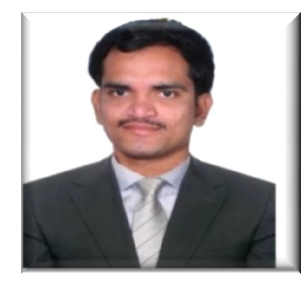

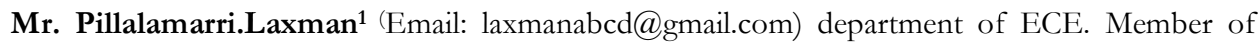
IAENG Society of Artificial Intelligence, Member of IAENG Society of Computer Science, Member of IAENG Society of Information System Engineering .Research Interests: Robotics and Control,VLSI. Academician from 2006. 


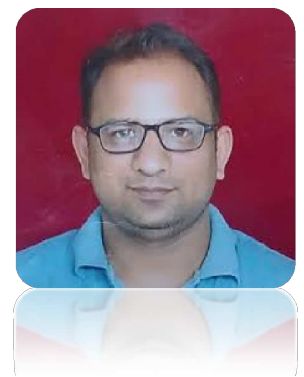

Dr.Anuj Jain working as a Professor. He obtained his Bachelor's degree in the field of Instrumentation in 2002 \& Master's degree in 2005 in Electronics and Communication. He is Complete his Ph.D. in the field of Electronics and Communication, in 2016. He is in teaching profession last 16.5 years and published 27 research papers in different referred journals and Conferences.10 PG(M.Tech) and 4 Ph.D's completed under his guidance till now. 


\section{Supplementary Files}

This is a list of supplementary files associated with this preprint. Click to download.

- DataAvailabilityStatements.docx 